\title{
Effect of posterior capsular opacification removal on automated perimetry
}

JJ García-Medina', M García-Medina², MT Arbona-Nadal ${ }^{1}$ and MD Pinazo-Duran ${ }^{3}$

\section{Abstract}

Purpose Although posterior capsular opacification (PCO) is a common phenomenon in a considerable number of ophthalmologic patients, no prospective controlled trials assessing its influence on automated perimetry exist. This technique continues as a standard in the diagnosis of glaucoma and neuroophthalmological diseases. The aim of the present report is to investigate the effect of PCO on automated visual field examination.

Methods A total of 26 PCO affected eyes of 26 patients had Humphrey SITA standard (program 24-2) immediately before, and between 1 and 8 weeks after

Neodymium: YAG capsulotomy. The effect of learning associated with repeated testing was controlled with automated perimetry before enrolment and visual fields of the fellow eye. Best-corrected visual acuity (BCVA), intraocular pressure (IOP), and global perimetric pre- and post-laser indices were compared using the Student's $t$-test for paired samples. Correlation and linear regression analyses were also performed.

Results BCVA and mean deviation (MD) improved following capsulotomy. Pattern standard deviation (PSD), an indicator of localized defects in the field, also improved significantly when PCO was solved. Moreover, a strong association among BCVA, MD, and PSD was shown both prior to and after capsulotomy.

Conclusion PCO is a heterogeneous mean opacity. This polymorphism may alter visual field results, and may even simulate the perimetric behaviour of other pathologies such as glaucoma. Consequently, the presence of PCO should be considered in the interpretation of any automated perimetry in pseudophakic patients. In addition, the values obtained before capsulotomy may partially predict the values obtained after capsulotomy. Eye (2006) 20, 537-545. doi:10.1038/sj.eye.6701918; published online 20 May 2005

Keywords: posterior capsular opacification; capsulotomy; visual field; automated perimetry; Humphrey

\section{Introduction}

Nowadays cataract removal with implantation of intraocular lens (IOL) in the capsular bag is the most frequent ophthalmic surgical procedure performed. The visual benefit obtained after this intervention may progressively suffer a decrease due to posterior capsular opacification (PCO). This long-term complication is caused by proliferation and centripetal migration (on the posterior capsule, as far as the blockage of visual axis) of lens remnant epithelial cells left in both the lens equator and anterior capsular bag following cataract extraction in the majority of cases. ${ }^{1}$

Significant differences exist among the published rates of PCO, yet a meta-analysis published in 1998 reported that overall, 25\% of patients undergoing extracapsular cataract extraction or phacoemulsification developed visually significant PCO within 5 years of the operation. ${ }^{2}$ The defect of visual acuity caused by PCO can usually be remedied by laser surgery with neodymium: YAG (Nd:YAG) capsulotomy to create an opening in the posterior lens capsule.

In spite of recent advances in imaging diagnostic methods, ${ }^{3-5}$ visual field analysis through white-on-white automated perimetry is a widely used technique that continues as a
${ }^{1}$ Department of Ophthalmology, University Hospital Doctor Peset,

Valencia, Spain

${ }^{2}$ Department of Ophthalmology,

Torrecardenas Hospital, Almería, Spain

${ }^{3}$ Head of the Ophthalmology Research Unit 'Santiago Grisolia', University Hospital Doctor Peset, Valencia, Spain

Correspondence: JJ GarcíaMedina, Department of Ophthalmology, University Hospital Doctor Peset, Avenida Gaspar Aguilar, 90, 46017 Valencia, Spain Tel: + 349638625 66; Fax: + 34963862500 . E-mail: josegarciam@ yahoo.com

Received: 25 December 2004

Accepted in revised form: 21 March 2005 Published online: 20 May 2005

The authors do not have any commercial interest in any product or procedure mentioned in this manuscript.

Presented in part at the 80th Congress of the Spanish Society of Ophthalmology, Cordoba, Spain, September-October 2004 
standard exploration to detect and follow-up glaucoma ${ }^{6}$ and neuro-ophthalmological diseases. ${ }^{78}$ Opacities in the anterior eyeball pole, such as cataracts or PCO, could be a confusing factor that may lead to an incorrect interpretation of automated perimetry, even when it is not uncommon to encounter patients who are affected, or are suspected to be affected, by various entities: $\mathrm{PCO}$ and glaucoma, or PCO and optic neuropathy for instance. The clinician must decide how much visual damage is caused by PCO, and how much is caused by the other disease.

Clinically, the cataract and PCO aspect upon slit-lamp examination is completely different: while the majority of cataracts present a homogeneous opacity, most common PCOs appear to have an unpredictable conformation, so a dissimilar perimetric behaviour is suspected.

The influence that cataracts have on automated perimetry has been well studied. ${ }^{9-11}$ Concerning PCO however, some studies have been undertaken by analysing its effects on visual acuity, contrast sensitivity, and glare, as well as on the improvement of these parameters after Nd:YAG capsulotomy, ${ }^{12-16}$ and also the influence of pseudophakia without PCO on kinetic ${ }^{17-20}$ or static perimetry. ${ }^{21,22}$ Nonetheless, no studies have analysed the perimetric behaviour of PCO.

In this study, we compared the characteristics of visual fields obtained with white-on-white automated perimetry from patients affected by PCO before and after $\mathrm{Nd}$ :YAG capsulotomy, and we determined the effect of PCO on the visual field.

\section{Materials and methods}

We contemplated all pseudophakic patients who came to our office complaining of decrease of visual acuity, glare, or other types of progressive visual discomfort for their possible inclusion in this study. Only those patients who underwent previous uneventful cataract surgery with acrylic IOL in the capsular bag were recruited, where the cause of visual alteration was exclusively due to PCO (patients with other pathology of the cornea, vitreous, macula, or optic nerve were excluded) after a complete ophthalmologic assessment, which included the following in this order: BCVA, slit-lamp examination, applanation tonometry, and retinal exam under pupilar dilation (tropicamide 1\% and phenylephrine 10\%). If $\mathrm{PCO}$ was detected after slit-lamp examination, the patient waited at least $15 \mathrm{~min}$, and subsequently, a visual field examination through automated perimetry whiteon-white SITA standard threshold strategy with Humphrey Field Analyzer II (model 740, Humphrey Instruments, Inc., Dublin, CA, USA) was performed by the same experienced perimetrist on both eyes, the fellow eye followed by the PCO-affected eye. Goldmann size III target was used. The results of this first visual field test were not considered for data analysis. The remaining examinations (applanation tonometry and funduscopy) were performed after automated perimetry.

Selected patients returned 1 week later, and they underwent identical visual field examination. Only those patients who did not surpass $20 \%$ false-positive or falsenegative responses on visual field examination remained in the study. Forthwith, patients underwent mydriasis (tropicamide $1 \%$ and phenylephrine $10 \%$ ) and Nd:YAG capsulotomy by the same surgeon. The laser treatment was initiated off axis in a vertical line across the centre, followed by a line on the horizontal axis to form a cross. The minimum amount of energy was used. In general terms, the aim was to create a capsulotomy size that approximately measured the minimum size required to exceed the pupillary diameter under scotopic conditions. Surgical eyes received one drop of apraclonidine $1 \%$ immediately after $\mathrm{Nd}$ :YAG, and $0.2 \%$ brimonidine twice daily for 7 days.

During the next visit, which was scheduled between 1 and 8 weeks after capsulotomy, an identical complete

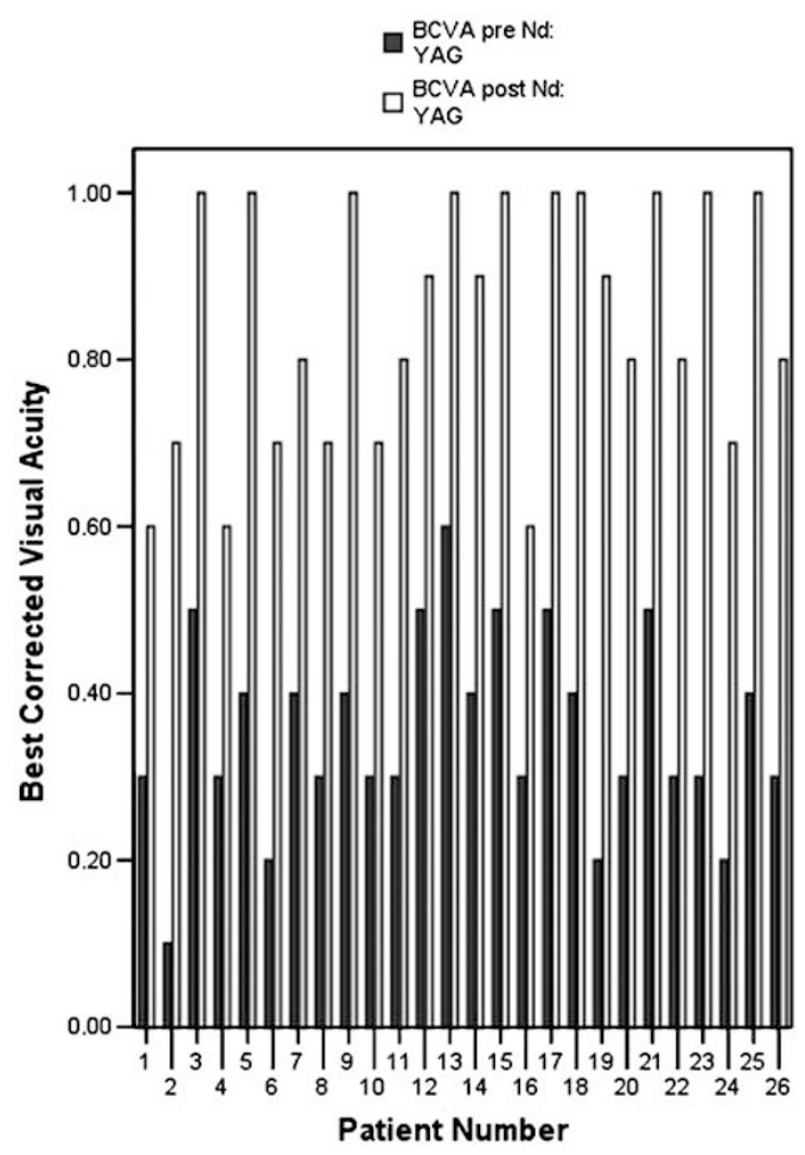

Figure 1 Summary of BCVA of PCO-affected eyes (treated with Nd:YAG laser) before and after capsulotomy. 
Table 1 Preoperative and postoperative global indices $(n=26)$

\begin{tabular}{|c|c|c|c|c|c|c|}
\hline & \multicolumn{3}{|c|}{ PCO-affected eye (treated) } & \multicolumn{3}{|c|}{ Fellow Eye (control, untreated) } \\
\hline & Preoperative & Postoperative & $P^{a}$ & Preoperative & Postoperative & $P^{\mathrm{a}}$ \\
\hline Mean deviation (MD) & $-6.77 \pm 2.55$ & $-3.31 \pm 1.77$ & $<0.001$ & $-3.84 \pm 2.01$ & $-3.75 \pm 1.89$ & 0.387 \\
\hline Pattern standard deviation (PSD) & $3.63 \pm 1.13$ & $2.24 \pm 0.94$ & $<0.001$ & $2.49 \pm 1.21$ & $2.38 \pm 1.17$ & 0.127 \\
\hline
\end{tabular}

Mean Values were expressed as the mean \pm standard deviation.

aPaired-samples Student's $t$-test

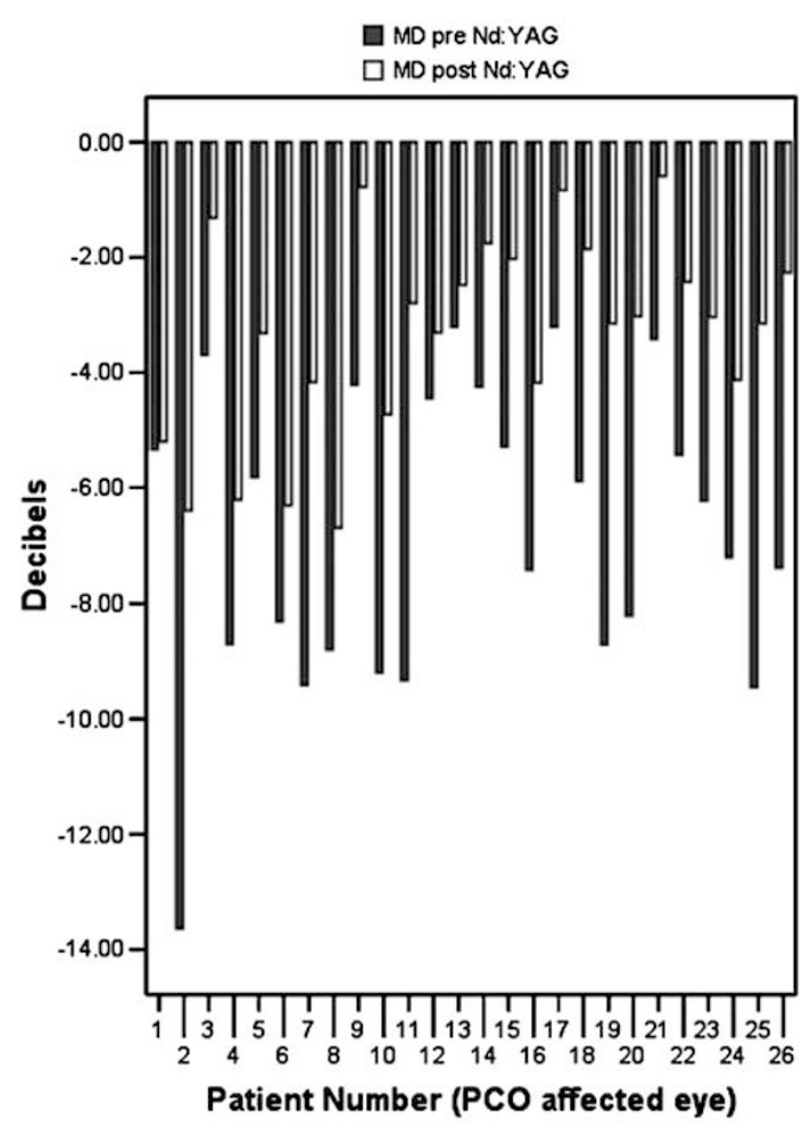

Figure 2 Summary of MD values of PCO-affected eyes (treated with $\mathrm{Nd}$ : YAG laser) before and after capsulotomy.

ophthalmic examination was performed including a control automated perimetry (with the same

characteristics and the same exclusion criteria as the previous test).

At the end of this prospective selection process, 30 eyes of 30 patients were affected by PCO without any other significant ocular pathology, carrying acrylic IOL in the capsular bag. Four of them were excluded in the first taken into account visual field examination (none in the second) as they exceeded $20 \%$ of false-positives or falsenegatives. Therefore, 26 eyes of 26 patients accomplished all the requirements described above. An informed

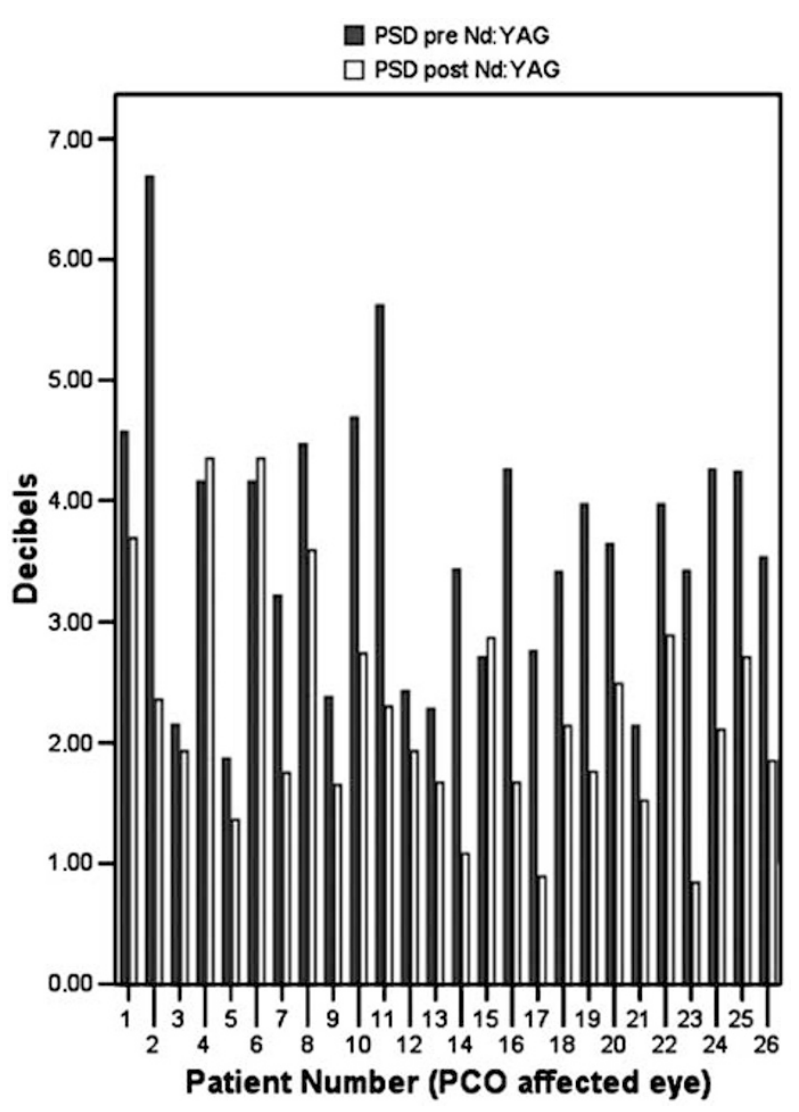

Figure 3 Summary of PSD values of PCO-affected eyes (treated with $\mathrm{Nd}$ : YAG laser) before and after capsulotomy.

consent was obtained from each patient before enrolment. All procedures conformed to the tenets of the Declaration of Helsinki. The study was approved by the local Ethics Committee.

\section{Results}

Statistical analysis was performed between preoperative and postoperative parameters by means of the pairedsamples Student's $t$-test.

Out of these 26 patients, 12 were men and 14 were women. The mean age was $67.65 \pm 8.03$ years (range 
51-83 years). The mean period between cataract extraction and development of visually disturbing PCO was $29.43 \pm 8.17$ months (range between 13 and 43 months). The 26 PCO-affected eyes were 13 right eyes and 13 left eyes.

The BCVA before and after Nd:YAG capsulotomy were $0.35 \pm 0.11$ and $0.84 \pm 0.14$, respectively, where a mean improvement of 4.92 lines on the Snellen chart after capsulotomy was observed $(P<0.001$, paired-samples Student's t-test) (Figure 1).

No significant difference $(P=0.83$, paired-samples Student's $t$-test) between mean preoperative $(17.5 \pm 2.4)$ and postoperative IOP $(17.42 \pm 2.31)$ was observed.

Postoperatively, not only the MD, but also the pattern standard deviation (PSD) revealed a statistically significant improvement after capsulotomy in 3.46 and 1.38 decibels $(\mathrm{dB})$, respectively. However, the same indices of fellow eyes remain unchanged (Table 1).

Detailed results of PCO-affected eyes (treated) (Figures 2 and 3) and fellow eyes (untreated) (Figures 4 and 5) are represented in the charts.

No retinal complications (such as peripheral degenerations, retinal tears or retinal detachments) were found either before nor after Nd:YAG was applied.

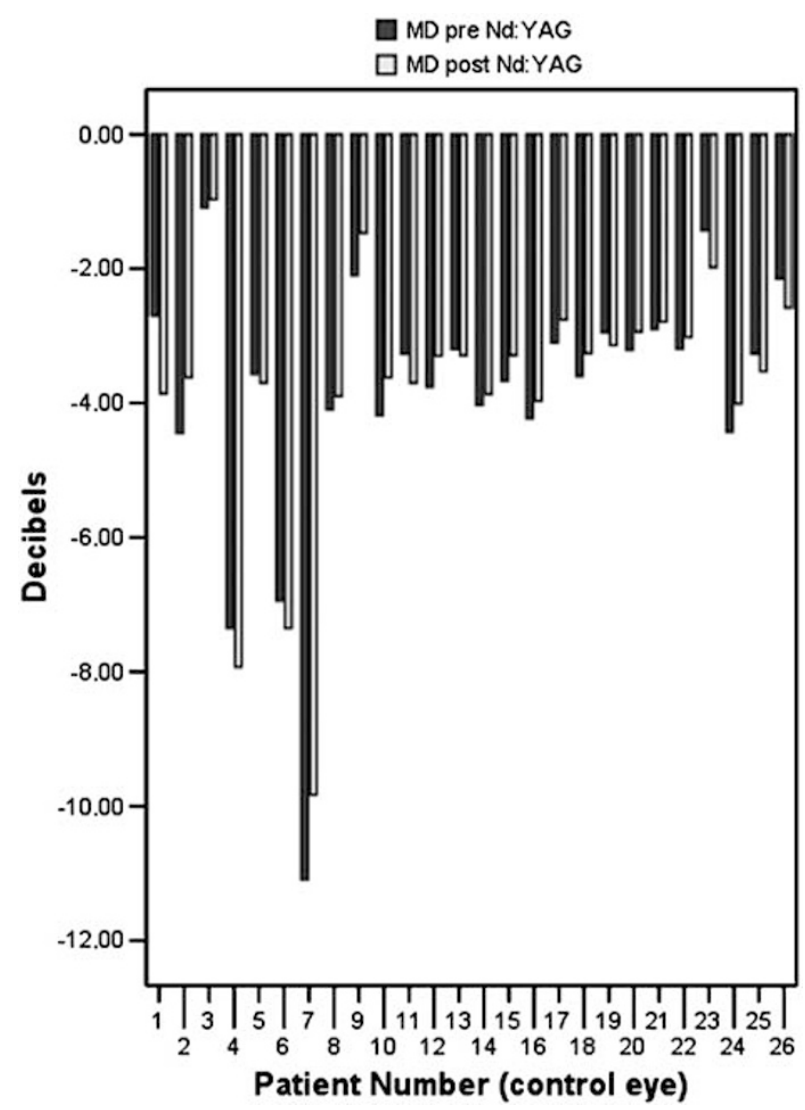

Figure 4 Summary of MD values of fellow eyes (control) before and after capsulotomy.
Bivariate associations analyses between BCVA, MD and PSD values (precapsulotomy and postcapsulotomy) were assessed using the Spearman correlation coefficient. Any differences showing a $P$-value of less than 0.05 were considered as statistically significant. There was a significant association among all variables to a greater or lesser extent (Table 2).

Simple linear regression analyses were also performed to assess the predictive capability of the different parameters before the capsulotomy. An increase of the BCVA precapsulotomy entailed an improvement of both the MD postcapsulotomy, and also the PSD postcapsulotomy to a lesser extent (Figures 6 and 7). Likewise, the worst MD and PSD values before the $\mathrm{Nd}$ : YAG application predicted the worst BCVA values after the capsulotomy (Figures 8 and 9).

\section{Discussion}

PCO shares many characteristics with cataracts as both interfere with light transmission to the retina. Visual acuity improves once this blockage effect has been suppressed (almost 5 lines after capsulotomy in this study).

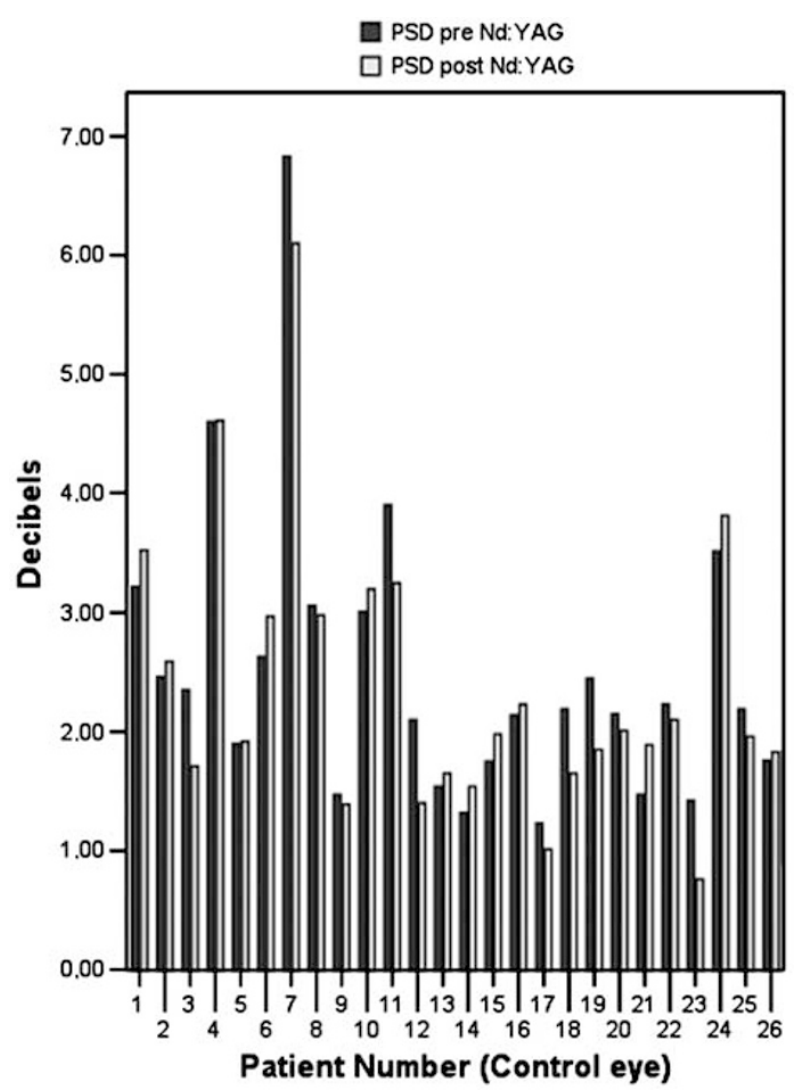

Figure 5 Summary of PSD values of fellow eyes (control) before and after capsulotomy. 
Table 2 Spearman correlations between BCVA, MD and PSD before and after capsulotomy

\begin{tabular}{|c|c|c|c|c|c|c|}
\hline \multirow[t]{2}{*}{ Spearman's rho } & \multicolumn{6}{|c|}{ Correlations } \\
\hline & VApre & MDpre & PSDpre & VApost & MDpost & PSDpost \\
\hline \multicolumn{7}{|l|}{ VApre } \\
\hline Correlation Coefficient & 1.000 & $0.681^{* *}$ & $-0.789^{* *}$ & $0.727^{* *}$ & $0.635^{* *}$ & $-0.443^{*}$ \\
\hline Sig. (two-tailed) & - & 0.000 & 0.000 & 0.000 & 0.000 & 0.024 \\
\hline$N$ & 26 & 26 & 26 & 26 & 26 & 26 \\
\hline \multicolumn{7}{|l|}{ MDpre } \\
\hline Correlation Coefficient & $0.681^{* *}$ & 1.000 & $-0.729^{* *}$ & $0.543^{* *}$ & $0.690^{* *}$ & $-0.485^{*}$ \\
\hline Sig. (two-tailed) & 0.000 & - & 0.000 & 0.004 & 0.000 & 0.012 \\
\hline$N$ & 26 & 26 & 26 & 26 & 26 & 26 \\
\hline \multicolumn{7}{|l|}{ PSDpre } \\
\hline Correlation Coefficient & $-0.789^{* *}$ & $-0.729^{* *}$ & 1.000 & $-0.787^{* *}$ & $-0.661^{* *}$ & $0.597^{* *}$ \\
\hline Sig. (two-tailed) & 0.000 & 0.000 & - & 0.000 & 0.000 & 0.001 \\
\hline$N$ & 26 & 26 & 26 & 26 & 26 & 26 \\
\hline \multicolumn{7}{|l|}{ VApost } \\
\hline Correlation Coefficient & $0.727^{* *}$ & $0.543^{* *}$ & $-0.787^{* *}$ & 1.000 & $0.765^{* *}$ & $-0.578^{* *}$ \\
\hline Sig. (two-tailed) & 0.000 & 0.004 & 0.000 & - & 0.000 & 0.002 \\
\hline$N$ & 26 & 26 & 26 & 26 & 26 & 26 \\
\hline \multicolumn{7}{|l|}{ MDpost } \\
\hline Correlation Coefficient & $0.635^{* *}$ & $0.690^{* *}$ & $-0.661^{* *}$ & $0.765^{* *}$ & 1.000 & $-0.527^{* *}$ \\
\hline Sig. (two-tailed) & 0.000 & 0.000 & 0.000 & 0.000 & & 0.006 \\
\hline$N$ & 26 & 26 & 26 & 26 & 26 & 26 \\
\hline \multicolumn{7}{|l|}{ PSDpost } \\
\hline Correlation Coefficient & $-0.443^{*}$ & $-0.485^{*}$ & $0.597^{* *}$ & $-0.578^{* *}$ & $-0.527^{* *}$ & 1.000 \\
\hline Sig. (two-tailed) & 0.024 & 0.012 & 0.001 & 0.002 & 0.006 & - \\
\hline$N$ & 26 & 26 & 26 & 26 & 26 & 26 \\
\hline
\end{tabular}

Significant at the 0.05 level (two-tailed).

*Correlation is significant at the 0.05 level (two-tailed).

${ }^{* *}$ Correlation is significant at the 0.01 level (two-tailed).

As far as IOP is concerned, no change was indicated in our study including a follow-up of between 1 and 8 weeks after capsulotomy. These results are in accordance with those obtained by Keates et al, since they found that the majority of IOP returned to the pretreatment level in 1 week post capsulotomy. ${ }^{23}$

In relation to visual field examination, we used the programme 24-2, which is accepted nowadays as the standard, given that it contains $99 \%$ of the information provided by $30-2$ but is $25 \%$ faster, so it involves less fatigue, and therefore less short-term fluctuation. ${ }^{24,25}$ The visual fields inclusion criterion was established in less than $20 \%$ for both false-positive and false-negative errors. This is more demanding than the perimeter manufacturers recommendations (Humphrey Instruments, Inc., Dublin, CA, USA), as they suggest less than $33 \%$ (for both types of errors) in order to obtain a reliable examination.

Otherwise, fixation losses were not considered as an inclusion criterion since there are circumstances in which a high rate of fixation losses could appear when the patient has actually maintained a good fixation. ${ }^{26}$

Results from the first automated perimetry were not taken into account as the aim of this test was to eliminate the learning effect. Although most normal patients will produce reliable results even in their first perimetric test, a significant minority of subjects will improve considerably with practice. ${ }^{27}$ This learning effect occurs mainly between the first and second visual fields. ${ }^{28}$

PCO-affected eye perimetry was performed after fellow eye perimetry in all patients in order to standardize the learning effect transfer from the first to the second examined eye within the test.

A visual field of the fellow eye (control eye) was also performed in each patient with the purpose of quantifying the possible learning effect between the considered pre- and post-laser automated perimetry. No significant learning effect was observed in our study (MD increase of $0.09 \mathrm{~dB}, P=0.387$; PSD decrease of 0.11 , $P=0.127)$ in the control eyes. We could, therefore, 


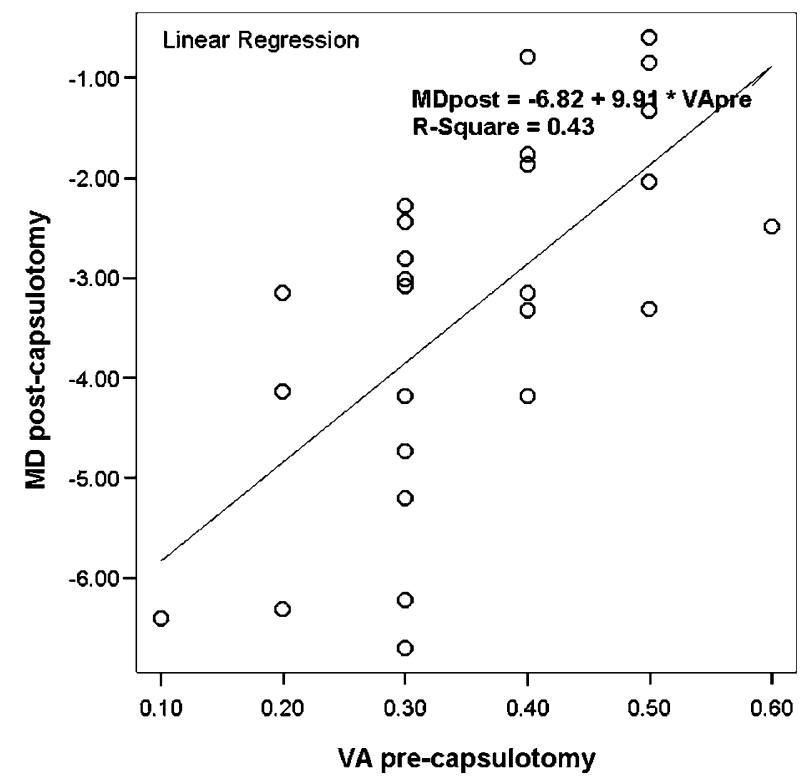

Figure 6 Scatter plot of BCVA precapsulotomy (independent variable) MD postcapsulotomy measurements (dependent variables). Linear regression function is represented. $R^{2}$ indicates the proportion of variation in the dependent variable (represented on the $y$-axis) that can be explained by the independent variable (represented on the $x$-axis).

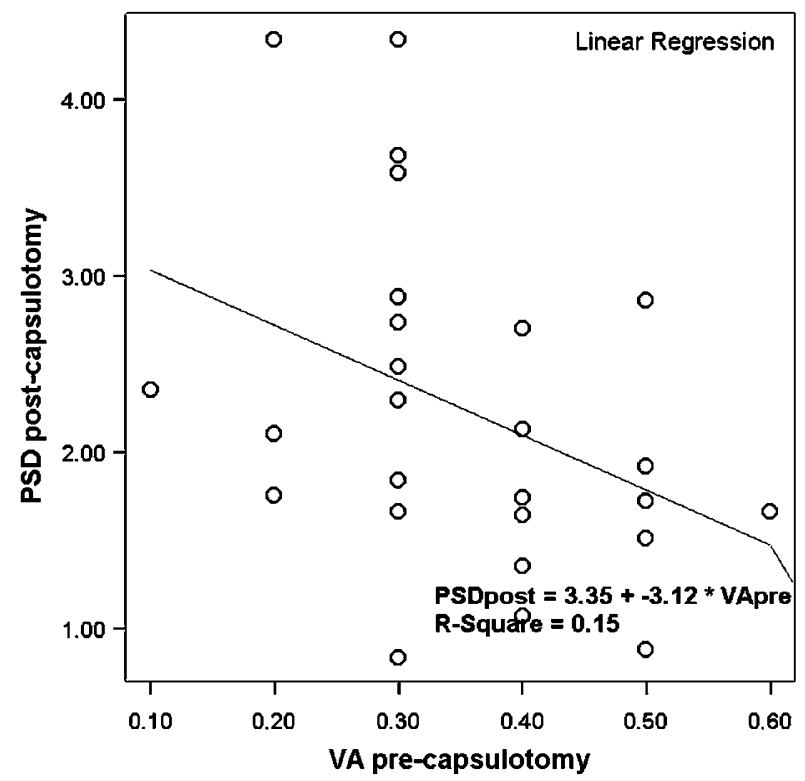

Figure 7 Scatter plot of BCVA precapsulotomy (independent variable) vs PSD postcapsulotomy measurements (dependent variables). Linear regression function is represented. $R^{2}$ indicates the proportion of variation in the dependent variable (represented on the $y$-axis) that can be explained by the independent variable (represented on the $x$-axis).

conclude that any MD and PSD changes in the PCO-affected eyes (hypothetically influenced by a similar learning effect) is due to capsulotomy.

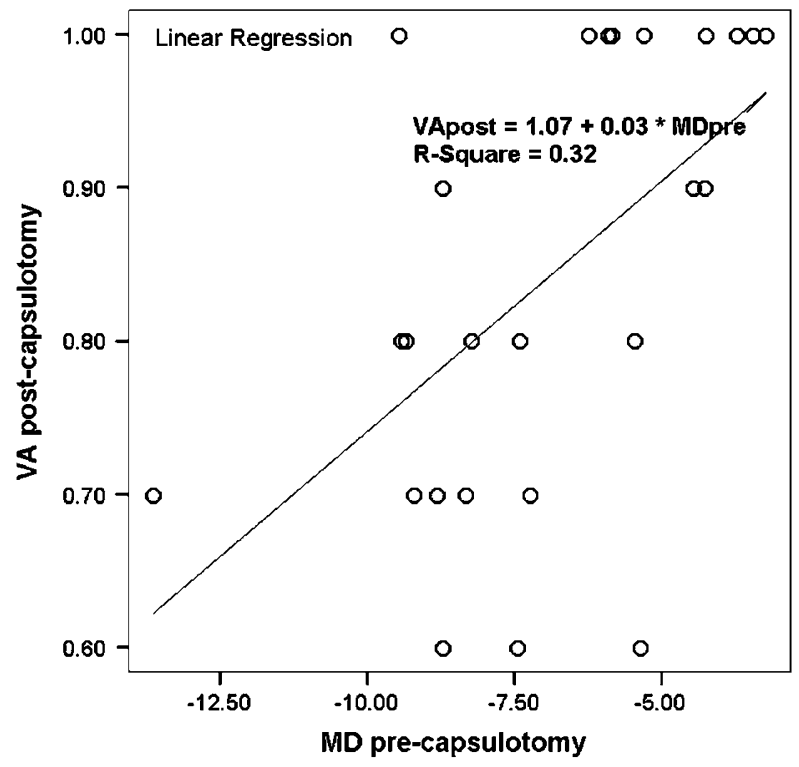

Figure 8 Scatter plot of MD precapsulotomy (independent variables) versus BCVA postcapsulotomy (dependent variable). Linear regression function is represented. $R^{2}$ indicates the proportion of variation in the dependent variable (represented on the $y$-axis) that can be explained by the independent variable (represented on the $x$-axis).

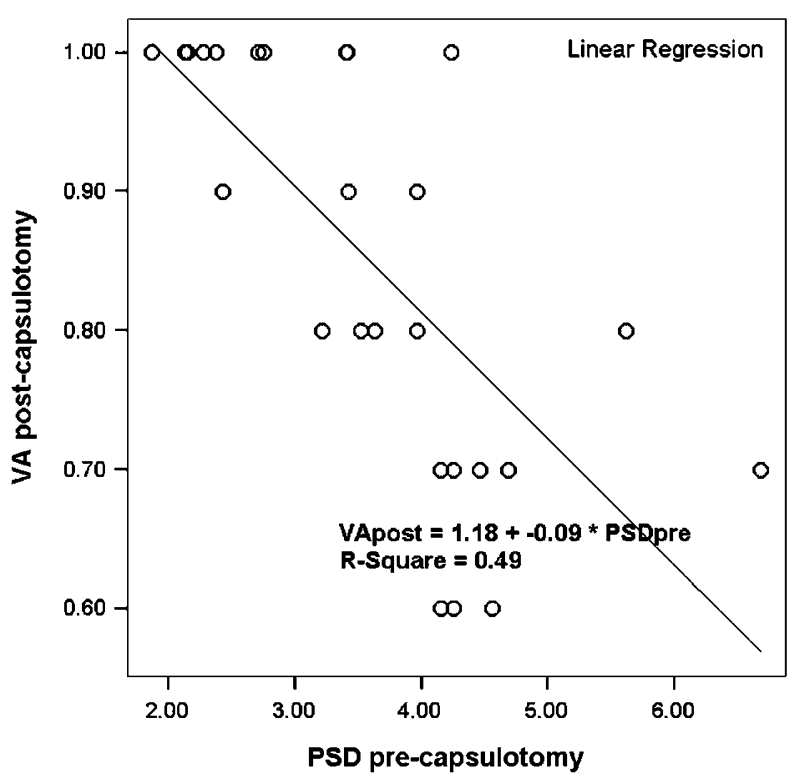

Figure 9 Scatter plot of PSD precapsulotomy (independent variables) versus BCVA postcapsulotomy (dependent variable). Linear regression function is represented. $R^{2}$ indicates the proportion of variation in the dependent variable (represented on the $y$-axis) that can be explained by the independent variable (represented on the $x$-axis).

Although visual acuity, contrast sensitivity, and glare have been demonstrated to be satisfactory in capsulotomies as small as $1.5 \mathrm{~mm}$ in diameter, even 
Central 24-2 Prueba de Umbral

PHG: Fuera de limites normales

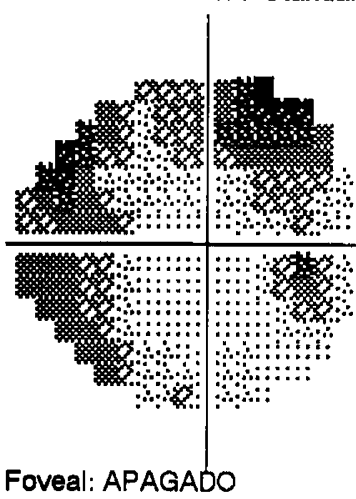

DM: $-9.33 \mathrm{~dB} P<0.5 \%$
FL: $2 / 18$

DSM: $5.62 \mathrm{~dB} P<0.5 \%$

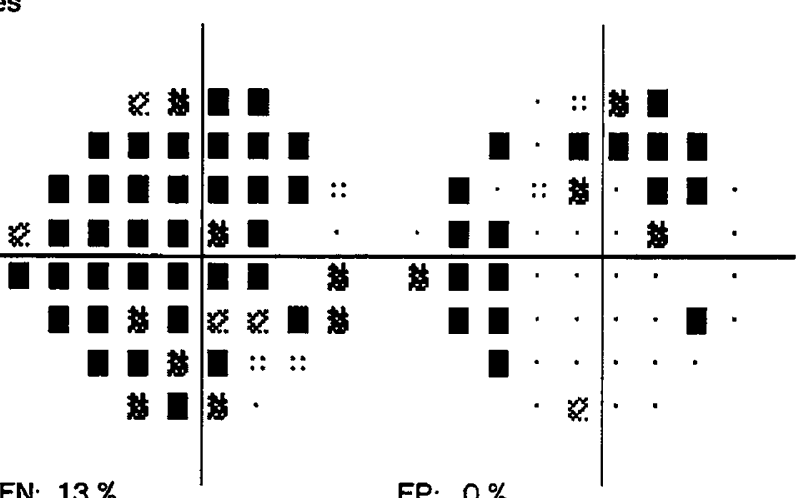

FN: $13 \%$

21-11-2002 SITA-Standard

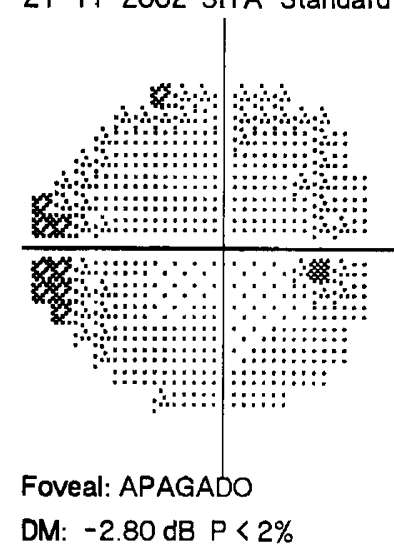

PHG: Dentro de Limites Normales

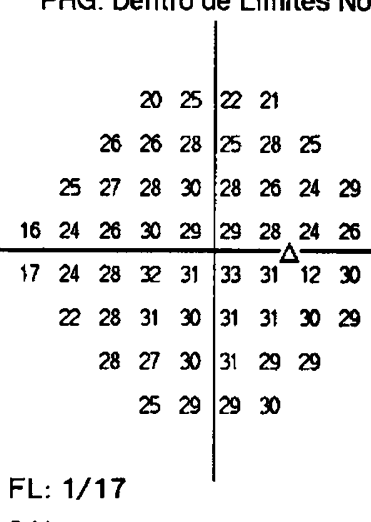

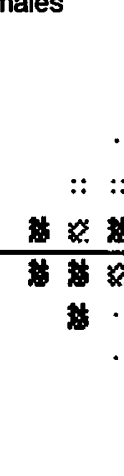

FN: $7 \%$

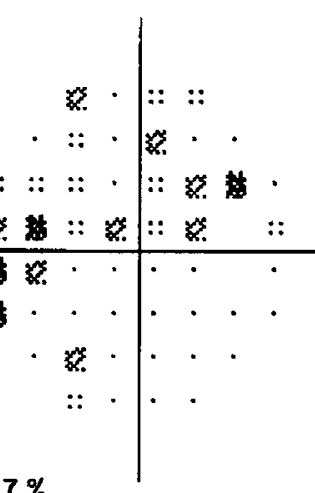

|: : :

$: \because \cdot \%$

DSM: $2.30 \mathrm{~dB} P<5 \%$

Figure 10 Visual field of right eye (PCO-affected) before and after capsulotomy in patient 11. Prelaser perimetry simulates an arcuate glaucomatous defect that disappears after laser therapy. Note important changes in DM and DSM. DM= MD, DSM=PSD, PHG $=$ Glaucoma Hemifield Test, $\mathrm{FL}=$ Fixation loss, $\mathrm{FN}=$ False-negative, $\mathrm{FP}=$ False-positive.

slightly decentred ones, ${ }^{29}$ in our study the size of capsulotomy was established as being larger than the pupillary diameter in dark conditions ${ }^{30}$ since a smaller capsulotomy size could affect the results of automated perimetry. $^{31}$

The test-retest interval (maximum eight weeks) was short enough to postulate that no true, detectable visual field progression occurred.

MD is the average measure of how depressed the patient's visual field is (compared with a normal person of the same age). Several researchers reported that MD improved after cataract surgery $\left(3.92 \mathrm{~dB},{ }^{9} 1.68 \mathrm{~dB},{ }^{10}\right.$ $\left.3.52 \mathrm{~dB}^{11}\right)$. Similarly, there was amelioration of MD after capsulotomy, according to our results $(3.46 \mathrm{~dB}$, $P<0.001)$.
PSD is a measure of how different the adjacent points are on a visual field. If an area is focally depressed, the PSD will rise given the great difference that exists between the points in the scotoma and their normal adjacent points. PSD remains unchanged after cataract removal (it worsens by $0.54 \mathrm{~dB}(P=0.09)^{10}$ or by 0.2 $(P=0.24),{ }^{9}$ and it improves by $\left.0.04(P=0.93)^{11}\right)$. In relation to $\mathrm{PCO}$ however, PSD improves by $1.38 \mathrm{~dB}$ after capsulotomy in our study $(P<0.001)$. This modification could be explained by the special $\mathrm{PCO}$ properties concerning reflection, refraction, and diffraction. PCO optical translucent imperfections presumably may cause irregular light-scatter within the eye, resulting in a combination of differently under-illuminated retinal areas and in an increase of PSD. Yet when these 


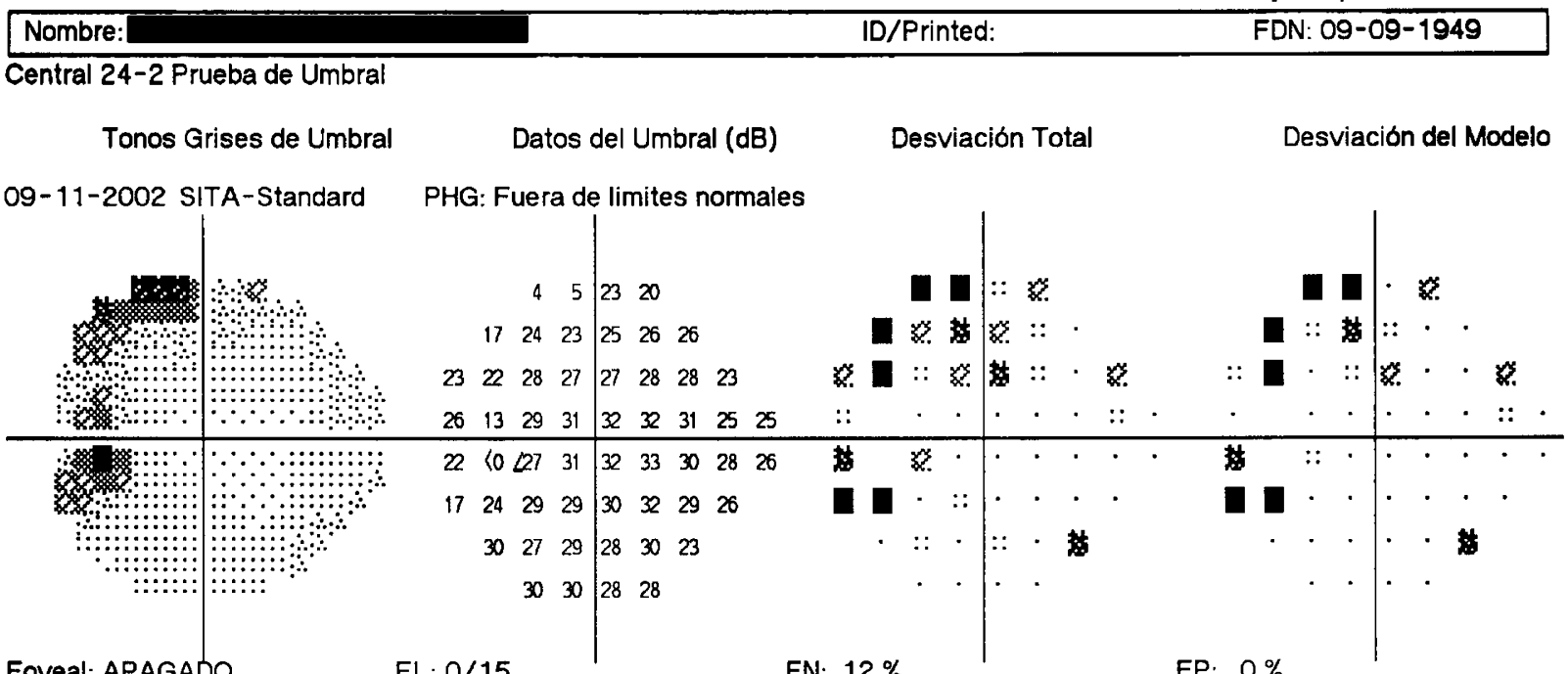

Foveal: APAGADO

FL: $0 / 15$

DSM: $3.90 \mathrm{~dB} P<0.5 \%$
FN: $12 \%$
FP: $0 \%$
DM: $-3.27 d B P<2 \%$

21-11-2002 SITA-Standard

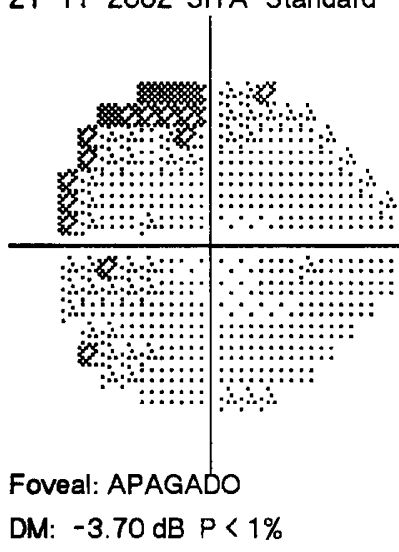

PHG: Caso Dudoso

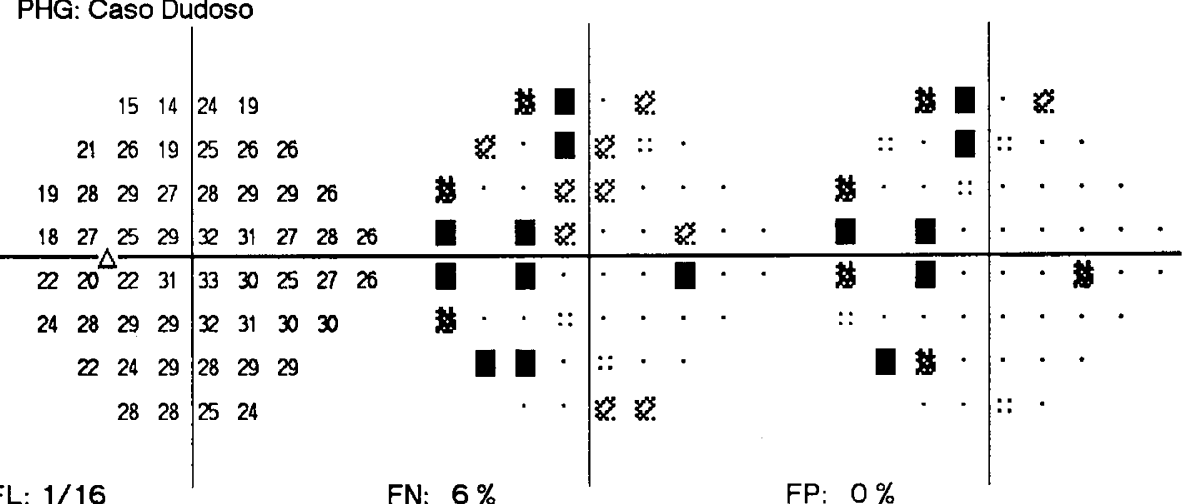

FL: $1 / 16$

FN: $6 \%$

FP: $0 \%$

DSM: $3.25 \mathrm{~dB} P<1 \%$

Figure 11 Visual field before and after capsulotomy of fellow eye (left eye, where no capsulotomy was performed) in patient 11. Note there is no significant change in DM or DSM. This eye is affected by a mild corticonuclear cataract. DM $=\mathrm{MD}, \mathrm{DSM}=\mathrm{PSD}$, $\mathrm{PHG}=$ Glaucoma Hemifield Test, $\mathrm{FL}=$ Fixation loss, $\mathrm{FN}=$ False-negative, $\mathrm{FP}=$ False-positive.

irregularities have been eliminated through capsulotomy, retinal illumination would be more uniform, so PSD decreases.

As the clinical slit-lamp examination impression suggests, and as the analysis of automated perimetry confirms, cataracts depress an automated visual field fairly uniformly, so they constitute homogeneous opacities. However, PCOs depress the visual field heterogeneously. They are, therefore, demonstrated as being polymorphous opacities that may even simulate pathological patterns, such as glaucoma arcuate scotoma, which are susceptible to elimination after capsulotomy (Figures 10 and 11).

As a result, it is necessary to consider the presence of $\mathrm{PCO}$ in the interpretation of visual fields in all pseudophakic patients since this entity may mislead the results, or may even mimic the perimetric behaviour of other pathologies.

The correlation results revealed a significant association among BCVA, MD and PSD, both prior to and after capsulotomy. The strong correlation between the BCVA and PSD precapsulotomies stands out. As is known, pear-type PCO produces a greater visual acuity decrease than the fibrosis-type PCO. ${ }^{1}$ Perhaps the PCOs with the worst visual acuity in this study are those with a greater rate of pearl formation, optical irregularities that would lead to an increase of PSD. Further study is necessary in this particular sense.

Linear correlation analyses indicate that BCVA precapsulotomy may better predict MD postcapsulotomy 
than PSD postcapsulotomy. Alternatively, MD precapsulotomy and PSD precapsulotomy are predictor parameters of BCVA postcapsulotomy.

All these conclusions are related to healthy subjects. However, more studies are necessary to discover whether these conditions are different in glaucomatous patients.

\section{Acknowledgements}

This work has been supported in part by EVES (Escuela Valenciana de Estudios para la Salud). We thank Dr M Morales for the statistical revision of data presented in this study.

\section{References}

1 Apple DJ, Solomon KD, Tetz MR, Assia EI, Holland EY, Legler UF et al. Posterior capsular opacification. Surv Ophthalmol 1992; 37: 73-115.

2 Schaumberg DA, Dana MR, Christen WG, Glynn RJ. A systematic overview of the incidence of posterior capsule opacification. Ophthalmology 1988; 105: 1213-1221.

3 Kaufman DI. Recent advances in neuro-imaging and the impact on neuro-ophthalmology. Curr Opin Ophthalmol 1994; 5: 52-62.

4 Lee AG, Hayman LA, Ross AW. Neuroimaging contrast agents in ophthalmology. Surv Ophthalmol 2000; 45: 237-253.

5 Stein DM, Wollstein G, Schuman JS. Imaging in glaucoma. Ophthalmol Clin North Am 2004; 17: 33-52.

6 Gonzalez de la Rosa MA. [Update on glaucoma diagnosis and follow-up]. Arch Soc Esp Oftalmol 2003; 78: 299-314.

7 Donahue SP. Perimetry techniques in neuro-ophthalmology. Curr Opin Ophthalmol 1999; 10: 420-428.

8 Wall M, Punke SG, Stickney TL, Brito CF, Withrow KR, Kardon RH. SITA standard in optic neuropathies and hemianopias: a comparison with full threshold testing. Invest Ophthalmol Vis Sci 2001; 42: 528-537.

9 Lam BL, Alward WL, Kolder HE. Effect of cataract on automated perimetry. Ophthalmology 1991; 98: 1066-1070.

10 Smith SD, Katz J, Quigley HA. Effect of cataract extraction on the results of automated perimetry in glaucoma. Arch Ophthalmol 1997; 115: 1515-1519.

11 Kim YY, Kim JS, Shin DH, Kim C, Jung HR. Effect of cataract extraction on blue-on-yellow visual field. Am J Ophthalmol 2001; 132: 217-220.

12 Sunderraj P, Villada JR, Joyce PW, Watson A. Glare testing in pseudophakes with posterior capsule opacification. Eye 1992; 6: 411-413.

13 Claesson M, Klaren L, Beckman C, Sjostrand J. Glare and contrast sensitivity before and after Nd:YAG laser capsulotomy. Acta Ophthalmol 1994; 72: 27-32.
14 Wilkins M, McPherson R, Fergusson V. Visual recovery under glare conditions following laser capsulotomy. Eye 1996; 10: 117-120.

15 Magno BV, Datiles MB, Lasa MS, Fajardo MR, Caruso RC, Kaiser-Kupfer MI. Evaluation of visual function following neodymium: YAG laser posterior capsulotomy. Ophthalmology 1997; 104: 1287-1293.

16 Aslam TM, Aspinall P, Dhillon B. Posterior capsule morphology determinants of visual function. Graefes Arch Clin Exp Ophthalmol 2003; 241: 208-212.

17 Meur G. [Peripheral visual acuity in aphakia and pseudophakia]. Bull Soc Belge Ophtalmol 1983; 204-205 55-60.

18 Flament J, Landre JC, Langer I, Piat JC. [The visual field of pseudophakic patients. Perimetric and statistical study]. J Fr Ophtalmol 1987; 10: 295-300.

19 Lazarus L, Williams TD. Visual field area in phakic, aphakic, and pseudophakic individuals. Am J Optom Physiol 1988; 65: 593-597.

20 Williams TD. Visual fields, acuity, and intraocular pressure in a pseudophakic patient. Optom Vis Sci. 1989; 66: 884-889.

21 Klewin KM, Radius RL, Schultz RO. Visual-field function in pseudophakia. Ann Ophthalmol 1988; 20: 316-317.

22 Nacef L, Jeddi A, Marrakchi S, Allagui M, Ayed S. [The visual field of patients with pseudophakia using kinetic and automated perimetry]. J Fr Ophtalmol 1992; 15: 405-409.

23 Keates RH, Steinert RF, Puliafito CA, Maxwell SK. Long term follow-up of Nd:YAG capsulotomy. J Am Intraocul Implant Soc 1984; 10: 164-168.

24 Flanagan JG, Wild JM, Trope GE. The visual field indices in primary open-angle glaucoma. Invest Ophthalmol Vis Sci 1993; 34: 2266-2274.

25 Roggen X, Herman K, Van Malderen L, Devos M, Spileers W. Different strategies for Humphrey automated perimetry: FASTPAC, SITA standard and SITA fast in normal subjects and glaucoma patients. Bull Soc Belge Ophtalmol 2001; 279: 23-33.

26 Alward WLM. Glaucoma. The Requisites in Ophthalmology, 1st ed., Mosby: St. Louis, 2000, pp 56-102.

27 Heijl A, Lindgren G, Olsson J. The effect of perimetric experience in normal subjects. Arch Ophthalmol 1989; 107: 81-86.

28 Heijl A, Bengtsson B. The effect of perimetric experience in patients with glaucoma. Arch Ophthalmol 1996; 114: 19-22.

29 Aslam TM, Dhillon B. Neodymium: YAG laser capsulotomy: a clinical morphological analysis. Graefes Arch Clin Exp Ophthalmol 2002; 240: 972-976.

30 Holladay JT, Bishop JE, Lewis JW. The optimal size of a posterior capsulotomy. J Am Intraocul Implant Soc 1985; 11: 18-20.

31 Chen F, Li RC, Wang J. [Effect of the different diameter of posterior capsulotomy on visual field]. Zhonghua Yan Ke Za Zhi 2003; 39: 294-297. 